\section{Lateral reading}

By Alexandra Pitman

'Some people think of psychiatry in very biomedical terms, whereas others proffer a highly psychosocial paradigm. ' Whether the content of the British Journal of Psychiatry reflects a balance between these two positions is an ongoing discussion at its editorial meetings. The other balance, which may be harder to achieve, is that between content reflecting the latest advances in neurosciences and mental health research, and content translating directly into benefits for people with mental health problems. This review of related content in the British Journal of Psychiatry's sister journals, Advances in Psychiatric Treatment and The Psychiatrist for the period June-November 2012, reflects their more clinically and educationally oriented perspectives, providing opportunities for further reading.

\section{Healthy bodies, healthy minds}

An editorial by Michael Marmot in September's Advances in Psychiatric Treatment summarised the range of inequalities associated with poor mental health, both as antecedents and consequences. Clear links are made to poor physical health, pointing out that 'since most mental illness arises by the time people reach their mid-20s, onset of mental disorder usually pre-dates physical illness by several decades, which means that mental disorder is an important driver as well as consequence of inequality.' World Mental Health Survey data published in June's British Journal of Psychiatry reminds us how much disability is associated with both mental and physical disorders. ${ }^{3}$ The importance of widening opportunities for physical activity in optimising mental health is highlighted in a number of related articles: describing the potential role of the Olympics in improving social inclusion through increased sports participation; ${ }^{4}$ the views of service users ${ }^{5}$ and practitioners ${ }^{6}$ on football projects for people with severe mental illness; the beneficial effects of structured exercise on depression severity in older people; ${ }^{7}$ and the need for collaborative tailored interventions ${ }^{8,9}$ to address the link between poor cardiovascular health and risk of later depression. ${ }^{10}$ A practical suggestion as to how people with severe mental illness might be motivated to make lifestyle changes is also described, following experiences in the Midlands. ${ }^{11}$

\section{Childhood disadvantage}

One of the recommendations Marmot makes in relation to reducing inequalities is to give every child the best start in life, suggesting improvements in parental input as one approach to this. A related article in October's British Journal of Psychiatry describes the negative impact of maladaptive parenting (harsh parenting and negative parental feelings) on the development of child self-control, demonstrating a link to later risk of emotional difficulties and conduct problems. ${ }^{12}$ However, by showing bidirectional effects, it also indicated how parental negative feelings can arise as a result of a child's low self-control. Given that other social adversities, such as those affecting sleeping, behaviour or feeding, ${ }^{13}$ may have a role in affecting childhood temperament, it is apparent that social injustice might act both as antecedent and consequence of childhood social and emotional adjustment. A trial published in the August issue of the British Journal of
Psychiatry suggests how Marmot's maxim might be reached. The school-based intervention to improve behaviour was set in Jamaica and found significant beneficial effects on conduct problems and social skills, with parents as well as teachers reporting reductions in behaviour difficulties. ${ }^{14}$ It is interesting to speculate what impact this had on parental negative feelings, and the role such a programme might have in addressing numerous upstream and downstream pathways to inequalities among young people.

\section{Assertive destigmatisation}

Marmot also mentions the discrimination associated with mental ill health, and how it can create a barrier to recovery. Although the mental health charities Mind and Rethink Mental Illness have garnered the support of the Department of Health and Comic Relief in their anti-stigma campaign, Time to Change, a study in October's The Psychiatrist found that unsolicited campaign material sent to members of the general public remained largely unread. ${ }^{15}$ Given that face-to-face approaches that are shown to be more effective, ${ }^{16}$ campaigns must be more assertive, which has worrying resource implications. A study in July's British Journal of Psychiatry added to the evidence for direct social contact as a means of reducing the stigma of mental ill health, by demonstrating that a DVD of filmed social contact was more cost-effective than either live contact or a lecture control. ${ }^{17}$

\section{Professional autonomy}

Stigma also affects mental health practitioners, and whether we perceive ourselves as valued professionals may have an impact on the quality of care offered to patients. A survey of staff morale on psychiatric wards and in community teams in July's British Journal of Psychiatry ${ }^{18}$ showed that emotional exhaustion was high in both settings, suggesting a link with the quality of support received from managers and colleagues. Although Burns' linked editorial questions how low morale might be addressed most effectively, and without recourse to further organisational reorganisation, ${ }^{19}$ a paper published in The Psychiatrist the same month provides a useful framework by which psychiatrists and other mental health professionals might improve autonomy from within. ${ }^{20}$ Applying these 'seven habits of highly effective people' offers each member of the mental health workforce, particularly those working in the most difficult settings, the chance to develop 'a much more realistic understanding of what he or she has to do, and what he or she can do. ${ }^{19}$

1 Hughes JC. Searching for real holism. Commentary on . . Paying attention. Adv Pychiatr Treat 2012; 18: 369-71.

2 Marmot M. Health inequalities and mental life. Adv Pychiatr Treat 2012; 18 $320-2$.

3 Bruffaerts R, Vilagut G, Demyttenaere K, Alonso J, AlHamzawi A, Andrade LH, et al. Role of common mental and physical disorders in partial disability around the world. Br J Psychiatry 2012; 200: 454-61.

4 Currie A. The London 2012 Olympics - will there be a legacy for mental health? Psychiatrist 2012; 36: 281-3.

5 Mason OJ, Holt R. A role for football in mental health: the Coping Through Football project. Psychiatrist 2012; 36: 290-3.

6 Nolot F, Védie C, Stewart A. Football and psychosis. Psychiatrist 2012; 36 307-9.

7 Bridle C, Spanjers K, Patel S, Atherton NM, Lamb SE. Effect of exercise on depression severity in older people: systematic review and meta-analysis of randomised controlled trials. Br J Psychiatry 2012; 201: 180-5.

8 de Jonge $P$, Roest AM. Depression and cardiovascular disease: the end of simple models. Br J Psychiatry 2012; 201: 337-8. 
9 Berk M, Jacka F. Preventive strategies in depression: gathering evidence for risk factors and potential interventions. Br J Psychiatry 2012; 201: 339-41.

10 Åberg MAl, Waern M, Nyberg J, Pedersen NL, Bergh Y, Åberg DN, et al. Cardiovascular fitness in males at age 18 and risk of serious depression in adulthood: Swedish prospective population-based study. Br J Psychiatry 2012; 201: 352-9.

11 Anderson N, Sridharan S, Megson M, Evans A, Vallance J, Singh S, et al. Preventing chronic disease in people with mental health problems: the HEALTH Passport approach. Psychiatrist 2012; 36: 208-13.

12 Cecil CAM, Barker ED, Jaffee SR, Viding E. Association between maladaptive parenting and child self-control over time: cross-lagged study using a monozygotic twin difference design. Br J Psychiatry 2012; 201: 291-7.

13 Ahamat BR, Minnis $\mathrm{H}$. Infant mental health: classification and relevance for clinicians. Psychiatrist 2012; 36: 230-4.

14 Baker-Henningham $\mathrm{H}$, Scott $\mathrm{S}$, Jones $\mathrm{K}$, Walker $\mathrm{S}$. Reducing child conduct problems and promoting social skills in a middle-income country: cluster randomised controlled trial. Br J Psychiatry 2012; 201: 101-8.
15 Mendes V, Maducolil Easow J, Luty J. Penetration of Time to Change leaflets on stigmatised attitudes to people with mental illness. Psychiatrist 2012; 36: 371-4.

16 Corrigan PW. Research and the elimination of the stigma of mental illness. Br J Psychiatry 2012; 201: 7-8.

17 Clement S, van Nieuwenhuizen A, Kassam A, Flach C, Lazarus A, de Castro $M$, et al. Filmed $v$. live social contact interventions to reduce stigma: randomised controlled trial. Br J Psychiatry 2012; 201: 57-64.

18 Johnson S, Osborn DPJ, Araya R, Wearn E, Paul M, Stafford M, et al. Morale in the English mental health workforce: questionnaire survey. Br J Psychiatry 2012; 201: 239-46.

19 Burns T. Where are the hypotheses when you need them? Br J Psychiatry 2012; 201: 178-9.

20 Jha A, Jha M. The seven habits of recovery-oriented psychiatrists: a non-clinical guide for personal growth and development. Psychiatrist 2012; 36: 345-8. 